\title{
Optimizing Strategies for Student Interaction in the Elementary School Classroom
}

\author{
Jinghui Zhang \\ Chenxinzhuang Central Primary School, Jizhou, Tianjin, China
}

\begin{abstract}
With the implementation of "new curriculum reform", the traditional teaching approaches are being improved. Researches indicate that various components contribute to the success in one's learning process with student-student interaction being an essential part. However, many investigations in China showed that student-student interaction hasn't been properly implemented in classroom atmosphere. In this study, current situations of student-to-student interaction in Chinese elementary school classroom are revealed. By analyzing factors influencing this form of interaction, the paper aims to put forward strategies in optimizing student-student interaction in the elementary school classroom.
\end{abstract}

Key words: student-student interaction; elementary school classroom; influencing factors; strategies

\section{Introduction}

Different factors in the teaching process influence the quality and efficiency of primary school education, such as the teaching style, the students affective variables, study circumstances, teaching hour arrangement, etc. In recent studies, the primary school classroom has paid special attention to student-student interaction after teacher-student interaction. It showed that student-student interaction is an effective way to realize teaching targets, and it has been seen as a major way in fostering students communicative and practical competence. A large amount of research has focused on the theoretical foundations for student-student interactions, the effect it brings to alleviate learning anxiety, improve sociability and enhance cooperation capacities. It is crucial to discuss how to encourage and optimize student-student interaction through analyzing the key factors in its practice.

\section{Current Form of Student-student Interaction in Elementary School}

Although the importance and effectiveness of student-student interaction has been acknowledged, investigations in Chinese elementary schools are not satisfactory in classroom student-student interaction, manifested as insufficient interaction, unreal interaction, superficial conversation. Teachers haven't played an effective role in student-student interaction, at the same time, students haven't mastered the skill of interacting with peers. Most interactions are between teacher and students, manifested as teacher asks and students answer. Otherwise, the student-student interaction groups are not flexible, the interaction activities are mainly proceed between desk mates or limited in adjacent seats (Chen Zhiqi \& Liang Jinlong, 2011). Lack of design for the interaction process make student-student interaction become a mere formality (Zhang Lina, 2010). In this situation, students talk to each other loudly and randomly, and they are not clear about what the new knowledge is, how to go through each step that is necessary in the interaction procedure, so they will not form a collective effort in a definite conversation direction. 


\section{Influencing Factors of Student-student Interaction}

Student-student interaction in class is proceeded among students, thus students' characters and mood will contribute or hinder the process of interaction. For this reason, the teachers should be familiar with each student's characters and arrange them properly in the interaction groups. Meanwhile, the interaction atmosphere should be regulated. Teachers' comprehensive teaching skills and emotional intelligence are essential factors that encourage student-student interaction. Otherwise, with the rapid development of information and communication technology, the way of interaction between students is also changed. To utilize the process of student-student interaction, teachers should give full play to their leadership role by improving teachers' guiding skills, students' sense of participation should be roused, and the educational information technology should also be taken full advantage of.

\section{Strategies in Utilizing Student-student Interaction}

4.1 Prepare for student-student interaction

\subsubsection{Arrange preparation for interaction}

Elementary school students are inadequate at knowledge reserve. At the same time, they are not good at exporting their knowledge and expressing opinions. Therefore, teachers should reveal the communication topic to students before class in order to guide them to prepare in advance. This way can not only facilitate students' interaction in class, but also enables them to collect information and self-study, which is a meaningful thing for students, for they can output it in class. Before-class preparation for interaction is a precious way to cultivate students' self-study habits.

In the classroom, enough time for independent thinking should also be reserved before students start to interact. Without preparation, students will not have a clear idea of how to cooperate and what to say in a group. Without selfthinking, a part of students who are not active in class may take the interaction process as granted, and they may speak very less and listen randomly as they haven't really thought over the questions by themselves. Thus, this group of students can not really benefit much in the interaction. And in most cases, the interaction without enough time to think ahead will become only a chance for the excellent students to share ideas, while the weak students will just play as passive listeners (Liu Xia, 2010). Otherwise, the interaction principles, object for communication and the interaction process should be clarified by teacher beforehand, for this can be an effective effort to make the interaction proceed more smoothly and orderly.

\subsubsection{Caring for students social role in class}

Classroom interaction helps improve students' social performance, while students' social role in class can also affect their interaction performance. Some students are unable to play popular social roles in class mainly due to their characters. A sociometric study of Davis et al. (2002) concluded that stuttering students who participated in classroom interaction were more likely to be rejected and less likely to be popular. Stuttering is often accompanied by shame, social concerns, and fear of negative evaluation in social situations (Bloodstein \& Ratner, 2008). So the support from friends can be a very important factor to protect these students from being injured by the passive evaluation of other students. What a teacher can do to help is arranging the stuttering students in a group which contains their friends at the outset till they become more familiar and confident in classroom interaction. Meanwhile, the teachers should pay attention to encouraging the students who are unable to actively talk in class due to timidity or lack of self-confidence to establish a good relationship with their peers. Positive peer relationships can act as butter to protect them in stressful interaction situations. The whole class unity should be established and cared by both teacher and students, hence to build a harmonious interactive atmosphere for student-student interaction. 


\subsection{In the process of interaction}

Teachers should focus on question design when preparing for a lesson. In order to make students active in thinking, the questions should be interesting and close to the students' real life. An investigation by Zhi Min (2019) showed that $95 \%$ teachers used the close questions as the main way in classroom question session. However, this simple way of questioning does not help encourage student-student interaction. In class, teachers should ask more open questions which are closely related to the students' real life and can arouse their speaking interest. At the same time, a teacher should observe the interaction process and guide the students in the right time. For example, when someone is digressing from the topic too far, the teachers should pull them back. When there are no more opinions to exchange in a group, teachers should lead the students to think about the relative questions and conduct future exchanges.

Questions should not only be raised by teachers, but also by students who are really taking part in the learning procedure. By asking questions, students will acquire questioning spirit, and by listening to the different opinions from their peers, they will know different ways of thinking. Interactions should not be limited in the same group, it should be extended to two different groups. This can be realized by posing questions to other groups and discussing a topic with other groups. In this way, the sense of group honor will be raised within a group, and the students will find this to be a challenging and interesting thing in the process of discussing with other groups.

\subsection{After interaction}

Interaction evaluation is a way to improve the interaction process. Teachers' evaluation is essential and authoritative for students. A lot of studies show that encouragement and positive evaluations from their peers are more credible and intimate for students. After the interaction, teachers should evaluate the interaction performance of the whole class, and take group or individual performance as an example to point out their good performance and shortcomings, so as to instruct students to improve the way students interact with students. In addition, we should especially attach importance to mutual evaluation between students. This process is a significant chance to foster trustworthy social relationships between students. Evaluation from interaction group members can be credible for students, for the group members who participated in the same interaction are more familiar with one's performance. Otherwise, evaluating yourself after interaction is also very helpful for the next student's performance in the group interaction. Besides, self-evaluation is a way of reflection and a course of initiation. These three ways of evaluation after interaction process are essential to improve interaction behavior and make adjustments in the following tasks.

\subsection{Utilization of educational information technology}

The rapid development of educational information technology has promoted the transformation of teaching and learning, which is mainly reflected in the classroom interaction. How to use the new technological equipment in classroom can make the effect of interaction different. Teachers and students should utilize the educational technology in classroom. And the classroom spatial arrangement can be more flexible and suitable for different classroom interactions. For example, the chairs and desks can be placed as round or honeycomb to suit different kind of interactions according to the teaching needs. In smart classroom which equipped computers for each student, teachers can arrange appropriate time for students to search information useful for interaction by themselves or in a group. The technology integrated interaction can be interesting and dynamic for the students. In order to use technology in the interaction process, teachers should go into the new software and technological equipment, and at the same time make a good design for how and when to use it in student-student interaction.

\section{Conclusions}

As the main activity of the elementary school classroom, student-student interaction has received more attention. 
Teachers and students should enhance their awareness of the importance of student-student interaction and play an active role in guiding and practicing this form of interaction in classroom. By following the trend of information technology evolution, teachers should renew their knowledge and skills in the use of educational technologies. Besides, they should make a comprehensive design before class, raise questions in right time and right way during class to encourage studentstudent interaction and arrange an effective evaluation after the interaction activity. Last but not the least, teachers should improve their integrated capacities, upgrade their methods of teaching and enhance their professional knowledge. By displaying a useful guiding role in classroom interaction, teachers can arouse students' enthusiasm for self-learning and communication, thus enable student-student interaction to a new level.

\section{Conflicts of Interest}

The author declares no conflicts of interest regarding the publication of this paper.

\section{References}

[1] Liu X. (2010). Research on Teaching Strategies Based on Interaction between Students and Students in Class. East China Normal University, Shanghai.

[2] Zhi M. (2019). Analysis of Interactive Behavior of Classroom Teaching in Smart Classroom Environment. Central China Normal University, Wuhan.

[3] Zhang L.N. (2010). Research on the Problems and Countermeasures in the Interactive Teaching of Primary School Classroom under Mode-Environment. Northwest Normal University, Lanzhou.

[4] Bloodstein O. and Ratner N.B. (2008). A Handbook on Stuttering (6th ed.). Thomson/Delmar Learning, Clifton Park, NY, 552.

[5] Davis S., Howell P. and Cooke F. (2002). Sociodynamic Relationships between Children Who Stutter and Their Non-stuttering Classmates. Journal of Child Psychology and Psychiatry, 43(7): 939-947. 